\title{
REVISED Estimating limits for natural human embryo mortality
}

\section{[version 2; peer review: 2 approved]}

\author{
Gavin E. Jarvis \\ Department of Physiology, Development and Neuroscience, University of Cambridge, Cambridge, CB2 3EG, UK
}

V2 First published: 26 Aug 2016, 5:2083

https://doi.org/10.12688/f1000research.9479.1

Latest published: 06 Dec 2016, 5:2083

https://doi.org/10.12688/f1000research.9479.2

\section{Abstract}

Natural human embryonic mortality is generally considered to be high. Values of $70 \%$ and higher are widely cited. However, it is difficult to determine accurately owing to an absence of direct data quantifying embryo loss between fertilisation and implantation. The best available data for quantifying pregnancy loss come from three published prospective studies (Wilcox, Zinaman and Wang) with daily cycle by cycle monitoring of human chorionic gonadotrophin (hCG) in women attempting to conceive. Declining conception rates cycle by cycle in these studies indicate that a proportion of the study participants were sub-fertile. Hence, estimates of fecundability and pre-implantation embryo mortality obtained from the whole study cohort will inevitably be biased. This new re-analysis of aggregate data from these studies confirms the impression that discrete fertile and sub-fertile sub-cohorts were present. The proportion of sub-fertile women in the three studies was estimated as $28.1 \%$ (Wilcox), $22.8 \%$ (Zinaman) and $6.0 \%$ (Wang). The probability of conceiving an hCG pregnancy (indicating embryo implantation) was, respectively, 43.2\%, $38.1 \%$ and $46.2 \%$ among normally fertile women, and $7.6 \%, 2.5 \%$ and $4.7 \%$ among sub-fertile women. Pre-implantation loss is impossible to calculate directly from available data although plausible limits can be estimated. Based on this new analysis and a model for evaluating reproductive success and failure it is proposed that a plausible range for normal human embryo and fetal mortality from fertilisation to birth is $40-60 \%$.

\section{Keywords}

early pregnancy loss, embryo mortality, human chorionic gonadotrophin, fecundability

\section{Open Peer Review \\ Approval Status \\ 1 \\ 2 \\ version 2 \\ (revision) \\ 06 Dec 2016 \\ version 1 \\ 26 Aug 2016

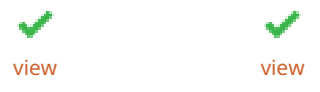

1. Stephen J. Senn (ID), Luxembourg Institute of Health, Strassen, Luxembourg

2. Alan O. Trounson, Monash University, Clayton, Australia

Any reports and responses or comments on the article can be found at the end of the article. 
Corresponding author: Gavin E. Jarvis (gej1000@cam.ac.uk)

Competing interests: No competing interests were disclosed.

Grant information: The author(s) declared that no grants were involved in supporting this work.

Copyright: @ 2016 Jarvis GE. This is an open access article distributed under the terms of the Creative Commons Attribution License, which permits unrestricted use, distribution, and reproduction in any medium, provided the original work is properly cited. Data associated with the article are available under the terms of the Creative Commons Zero "No rights reserved" data waiver (CC0 1.0 Public domain dedication).

How to cite this article: Jarvis GE. Estimating limits for natural human embryo mortality [version 2; peer review: 2 approved] F1000Research 2016, 5:2083 https://doi.org/10.12688/f1000research.9479.2

First published: 26 Aug 2016, 5:2083 https://doi.org/10.12688/f1000research.9479.1 


\section{REVISED Amendments from Version 1}

This new version includes more formal definitions of conditional probabilities that are quantified in the study. It is hoped that this will clarify the meaning of the estimates.

See referee reports

\section{Introduction}

Estimates of natural human embryo mortality have been derived using speculative calculations ${ }^{1}$, mathematical modelling ${ }^{2}$, pregnancy surveys ${ }^{3}$, and a unique collection of surgical material ${ }^{4,5}$. Three well-designed studies (henceforth referred to as the Wilcox ${ }^{6}$, Zinaman $^{7}$ and $\mathrm{Wang}^{8}$ studies) have shown that approximately two-thirds of menstrual cycles in which elevated human chorionic gonadotrophin (hCG) is detected approximately 1 week after ovulation proceed to a live birth. hCG is produced by the trophoblast cells of the embryo ${ }^{9}$ and its earliest detection indicates that implantation has commenced ${ }^{10-12}$. Hence, these studies provide no direct measure of embryo loss before implantation. The only measure of pre-implantation loss is the "scanty data of Hertig" 13 which have generated estimates 4,5 that are "difficult to defend with any precision" 2 . Estimates of embryo mortality from fertilisation onwards are therefore subject to considerable uncertainty owing to the absence of suitable data for the 5-7 day period between fertilisation and implantation.

Fecundability is the probability of reproductive success per cycle. Compared to other animals, fecundability in humans is low and has been estimated at $<35 \%{ }^{14,15}$. Red deer hinds, by contrast, achieve pregnancy rates of $>85 \%$ per natural mating ${ }^{16}$. Clearly, as fecundability increases, the range of plausible values for embryo mortality narrows. Crude estimates of live birth fecundability can be calculated from prospective study data: $19.2 \%$ (136 births from 707 cycles $^{6}$ ), $18.2 \%$ (79 births from 432 cycles $^{7}$ ) and 23.9-25.9\% (373 births and 31 ongoing pregnancies from 1,561 cycles ${ }^{8}$ ). These represent lower limits for fecundability, since optimal conditions for reproductive success were not achieved in every cycle ${ }^{17}$. However, some published estimates of embryo mortality, e.g., $76 \%{ }^{2,18}$ and $78 \%^{1}$ can only be reconciled with these data if it is assumed that almost every non-birth cycle in these studies resulted in successful fertilisation and subsequent embryonic or fetal death, an extreme and improbable condition. Higher estimates of embryo mortality, including $>85 \%{ }^{19}$ and $90 \%{ }^{20}$, are even less plausible. Furthermore, it is self-evident that not all observed reproductive failure is necessarily due to embryo or fetal mortality: other biological causes include mistimed coitus and failure of fertilisation despite in vivo co-localisation of ovum and sperm. Estimates of embryo mortality based on fecundability must take this into account.

The objective of this study is to obtain plausible estimates of fecundability and early human embryo mortality from available published data ${ }^{6-8}$. To do this, a simple quantitative framework is proposed to define a successful reproductive cycle. Hence, for a menstrual cycle to conclude with a live infant several distinct biological stages must be completed, each with its own probability $(\pi)$ of success. These stages (and conditional probabilities) are defined as follows: (1) sexual activity within a cycle resulting in sperm-ovum-co-localisation $\left(\pi_{S O C}\right)$; (2) subsequent successful fertilisation $\left(\pi_{F E R T}\right)$; (3) initiation of implantation approximately 1 week after fertilisation as indicated by increased levels of hCG $\left(\pi_{H C G}\right)$; (4) progression to a clinical pregnancy $\left(\pi_{C L I N}\right)$ : the earliest typical clinical indication is an absent menstrual period approximately 14 days after fertilisation, although definitions of clinical pregnancy vary between studies; (5) survival of a clinical pregnancy to a live birth $\left(\pi_{L B}\right)$. Conditional probabilities are defined more formally as follows:

If $\mathrm{P}(\mathrm{A} \mid \mathrm{B})$ is the probability of event $\mathrm{A}$, conditional on event $\mathrm{B}$, then:

i. $\pi_{L B}=\mathrm{P}(\mathrm{A} \mid \mathrm{B})$, where $\mathrm{A}$ is a live birth, and $\mathrm{B}$ is a clinical pregnancy

ii. $\quad \pi_{C L I N}=\mathrm{P}(\mathrm{A} \mid \mathrm{B})$, where $\mathrm{A}$ is a clinical pregnancy, and $\mathrm{B}$ is a positive hCG test

iii. $\pi_{H C G}=\mathrm{P}(\mathrm{A} \mid \mathrm{B})$, where $\mathrm{A}$ is a positive hCG test, and $\mathrm{B}$ is successful fertilisation

iv. $\quad \pi_{F E R T}=\mathrm{P}(\mathrm{A} \mid \mathrm{B})$, where $\mathrm{A}$ is successful fertilisation, and $\mathrm{B}$ is the in vivo co-localisation of ovum and sperm

v. $\quad \pi_{S O C}=\mathrm{P}(\mathrm{A} \mid \mathrm{B})$, where $\mathrm{A}$ is the in vivo co-localisation of ovum and sperm, and B a single menstrual cycle

It is therefore possible to calculate four different fecundabilities (broadly following Leridon $^{21}$ ):

$$
\begin{aligned}
& \text { 1. Total (All fertilisations): } \quad F E C_{T O T}=\pi_{S O C} \times \pi_{F E R T} \\
& \text { 2. Detectable (Implantation): } F E C_{H C G}=\pi_{S O C} \times \pi_{F E R T} \times \pi_{H C G} \\
& \text { 3. Apparent (Clinical): } \quad F E C_{C L I N}=\pi_{S O C} \times \pi_{F E R T} \times \pi_{H C G} \times \pi_{C L I N} \\
& \text { 4. Effective (Live Birth): } \quad F E C_{L B}=\pi_{S O C} \times \pi_{F E R T} \times \pi_{H C G} \times \pi_{C L N} \times \pi_{L B}
\end{aligned}
$$

Quantitative differences between these fecundabilities reflect intrauterine mortality at different developmental stages. Hence, the probability that a fertilised egg will perish prior to implantation is $\left[1-\pi_{H C G}\right]$, and prior to clinical recognition is $\left[1-\left(\pi_{H C G} \times \pi_{C L I N}\right)\right]$. In theory, embryonic mortality may be estimated at all stages although in practice this depends on available data.

In 1969, Barrett \& Marshall analysed the relationship between coital patterns and conception and concluded that fecundability increased with coital frequency up to $68 \%$ for daily intercourse ${ }^{22}$. Schwartz's re-analysis of the same data revealed a similar pattern, although at higher coital frequencies estimated fecundability was lower, at $49 \%$ for daily intercourse ${ }^{23}$. These analyses indicate that failure to conceive at coital frequencies of less than once per day is, in part, due to mistimed coitus and not solely failure of fertilisation and/or embryo mortality. The difference in their estimates of fecundability arises because of key differences between the two analyses. Firstly, Schwartz analysed 2,192 cycles, 294 more than Barrett \& Marshall. Secondly, the measures of conception differed: Barrett \& Marshall used "absence of menstruation, after ovulation", approximately 2 weeks after ovulation, whereas for Schwartz conception was "defined as a pregnancy lasting at least 2 months from the last menstrual period", i.e., approximately 6 weeks from the day of ovulation. It is not surprising therefore 
that Schwartz values were lower since they will not have captured pregnancies that failed between 2 and 6 weeks post-fertilisation. Thirdly, and importantly, Schwartz introduced a new term, 'cycle viability', into the analytical model.

Schwartz modelled the probability of conceiving during a cycle (i.e., fecundability, $F E C$ ) as the product of three conditional probabilities as follows: $F E C=P_{o} P_{f} P_{v} . P_{o}, P_{f}$ and $P_{v}$ were the probabilities that (i) a fertilisable egg is produced $\left(P_{o}\right)$, (ii) it is fertilised once produced $\left(P_{f}\right)$, and (iii) it survives to be detected as a conception $\left(P_{v}\right) . P_{f}$ was modelled as a function of coital frequency. Cycle viability $(k)$ was defined as $k=P_{o} P_{v}$, and allows for the possibility that optimally-timed coitus would not result in a detected conception. It implies that there is a proportion of cycles that are infertile irrespective of coital activity. Although Schwartz did not explicitly report statistical data demonstrating that the extra parameter $(k=52 \%)$ improved the quality of the model, a comparison of the Barrett \& Marshall and Schwartz models using the Wilcox study data $^{6}$ provided compelling statistical evidence to this effect, and concluded that only $37 \%$ of cycles were "viable" 24 .

Since cycle viability $(k)$ includes terms defining reproductive success both before $\left(P_{o}=\right.$ successful ovulation $)$ and after $\left(P_{v}=\right.$ embryo survival) fertilisation, it is not possible to use this term to make direct inferences about early embryo mortality. Nevertheless, Schwartz assumed that $P_{o}=100 \%$, thereby interpreting all cycle non-viability as a consequence of embryo loss at a rate of $48 \%$ during the first 6 weeks after fertilisation. Similar logic applied to the Wilcox study ${ }^{24}$ would conclude an equivalent estimate of $63 \%$ embryo mortality. Schwartz also concluded that $P_{f}=94 \%$ for daily intercourse $(0.49 / 0.52)$. Hence, Schwartz attributed almost all the observed reproductive inefficiency to embryo mortality and other processes of the reproductive process were, by implication, considered to work almost perfectly. By contrast, referring to fertilisation, Hertig noted that "it seems unlikely that such a complicated process should work perfectly every time" ${ }^{5}$. It has also been correctly pointed out that preimplantation loss is statistically indistinguishable from other causes of cycle non-viability including male factors ${ }^{15}$. It seems that this interpretation of reproductive inefficiency has contributed to a widespread impression that early human embryo mortality is very high.

What are the potential explanations for cycle non-viability? Incorporation of a between-couple random effect into the modelling of these data has confirmed that cycle viability is heterogeneous between couples ${ }^{15}$. A subject-specific random effects modelling approach also resulted in a more consistent cycle by cycle estimate of cycle viability ${ }^{25}$. These analyses formally demonstrate that within the cohorts of women used in this study, there were individual differences in fecundability. Furthermore, in the Wilcox study, 14 out of 221 women were unable to conceive within 24 months ${ }^{6}$ : this observation alone suggests that a proportion of the study participants were sub-fertile.

Each of the three hCG studies sought to recruit normally fertile, non-contracepting women who intended to conceive. Subjects either had "no known fertility problems", or were excluded if they had any "known risk factors for infertility" or "had tried unsuccessfully to get pregnant for $\geq 1$ year at any time in the past"8. However, such criteria cannot guarantee complete exclusion of sub-fertile or infertile couples, and in each study pregnancy rates declined in successive cycles as the presumed proportion of subfertile women remaining increased. Hence, calculations based on overall aggregate data underestimate fecundability in normally fertile women. Even estimates based on first cycle data are likely to be biased since a proportion of sub-fertile of women would be in the starting cohort. The extent of the bias of such estimates will depend on factors including the heterogeneity of the population and the number of cycles studied.

Estimates for $F E C_{H C G}$ of $30 \%^{7}$ and $40 \%^{8}$, and for $F E C_{C L I N}$ of $30 \%{ }^{8}$ and $25 \%$ probably underestimate the fecundability of reproductively healthy women owing to a mixed fertile/sub-fertile population in these studies. The object of the present analysis was to determine whether the published aggregate data supported this hypothesis and to estimate fecundability for any sub-cohorts identified. The modelling approach is conceptually simple; nevertheless, the results strongly indicate that the hypothesis is true and therefore provide less biased estimates of fecundability for reproductively normal women. These higher estimates of fecundability narrow the range of plausible values for embryo mortality in normal fertile women.

\section{Methods}

Data were obtained from Table 2 of Wilcox ${ }^{6}$, Table 3 and Figure 1 of Zinaman ${ }^{7}$ and Table 2 of Wang ${ }^{8}$ studies. Fourteen women who did not conceive after 24 months were included in the analysis of the Wilcox data (1 reproductive cycle per month was assumed). A subsequent publication reported an extra cycle and an extra hCG pregnancy ${ }^{26}$; however, it is not clear in which cycle this occurred,

Table 1. Parameter values and statistical output from best fit models (Model 0) of the data from Wilcox (1988), Zinaman (1996) and Wang (2003) studies. Probabilities and percentages were estimated as logits (base 10). Standard errors are shown. Actual probabilities with 95\% confidence intervals are reported in Figure 1. Two alternatively parameterised (Model 0 \& Model 00) but statistically identical models were used to obtain standard errors for $F E C_{H C G}$ and $F E C_{C L I N}$ since $F E C_{C L I N}=F E C_{H C G} \times \pi_{C L I N}(E L S=$ extended least squares; dof $=$ degrees of freedom.)

\begin{tabular}{|c|c|c|c|}
\hline Parameter & Wilcox (1988) & Zinaman (1996) & Wang (2003) \\
\hline $\begin{array}{l}\% \text { fert }_{(1)} \\
\text { FEC } \\
F E C_{\text {HCGIFERT }} \\
F E C_{\text {HCG/SUERT }} \\
F E C_{C L I N / S U B F} \\
\pi_{C L I N} \\
\sigma \\
\gamma\end{array}$ & $\begin{aligned} 0.408 & \pm 0.085 \\
-0.118 & \pm 0.066 \\
-0.291 & \pm 0.043 \\
-1.087 & \pm 0.091 \\
-1.200 & \pm 0.086 \\
0.558 & \pm 0.099 \\
0.437 & \pm 0.090 \\
1.26 & \pm 0.14\end{aligned}$ & $\begin{array}{c}0.529 \pm 0.145 \\
-0.211 \pm 0.049 \\
-0.301 \pm 0.057 \\
-1.598 \pm 0.476 \\
-1.657 \pm 0.477 \\
0.845 \pm 0.165 \\
1.250 \pm 0.686 \\
0.47 \pm 0.37\end{array}$ & $\begin{array}{c}1.194 \pm 0.167 \\
-0.066 \pm 0.029 \\
-0.271 \pm 0.018 \\
-1.304 \pm 0.383 \\
-1.431 \pm 0.378 \\
0.488 \pm 0.043 \\
0.870 \pm 0.193 \\
0.84 \pm 0.13\end{array}$ \\
\hline $\begin{array}{l}N \\
\text { parameters } \\
\text { dof } \\
\text { ELS }\end{array}$ & $\begin{array}{c}27 \\
6 \\
21 \\
52.6707\end{array}$ & $\begin{array}{c}26 \\
6 \\
20 \\
73.0862\end{array}$ & $\begin{array}{c}41 \\
6 \\
35 \\
119.209\end{array}$ \\
\hline
\end{tabular}


Table 2. Statistical results of hypothesis tests comparing the models shown in Table 1 (Model 0 ) with alternative models. Degrees of freedom (dof) is the difference in the number of estimated parameters between the models. $\chi^{2}$ is the difference in objective function values $(E L S)$ for the two models. P values were calculated using likelihood ratio tests. The models are defined in brackets. $H_{0}$ is the null hypothesis. $H_{1}$ is the alternative hypothesis. NONMEM control files are named according to the study and the model, e.g., Model 0 for the Wang data is WANGO.ctl.

\begin{tabular}{|c|c|c|c|c|c|c|}
\hline $\begin{array}{l}\text { Hypothesis } \\
\text { Test }\end{array}$ & $\mathrm{H}_{0}$ & $\mathrm{H}_{1}$ & dof & $\begin{array}{c}\text { Wilcox (1988) } \\
\chi^{2}, P\end{array}$ & $\begin{array}{c}\text { Zinaman (1996) } \\
\chi^{2}, P\end{array}$ & $\begin{array}{c}\text { Wang (2003) } \\
\chi^{2}, P\end{array}$ \\
\hline 1 & $\begin{array}{c}F E C_{\text {HCG/FERT }}=F E C_{\text {HCG/SUBF }} \\
(\text { Model 1) }\end{array}$ & $\begin{array}{c}F E C_{\text {HCG/FERT }} \neq F E C_{\text {HCG/SUBF }} \\
(\text { Model O) }\end{array}$ & 2 & $54.0,2 \times 10^{-12}$ & $54.9,1 \times 10^{-12}$ & $69.5,8 \times 10^{-16}$ \\
\hline 2 & $\begin{array}{c}2 \text { FEC } C_{H C G} \text { sub-cohorts } \\
\text { (Model 0) }\end{array}$ & $\begin{array}{c}3 F E C_{H C G} \text { sub-cohorts } \\
\text { (Model 2) }\end{array}$ & 2 & $0.00,1.00$ & $0.65,0.72$ & $0.00,1.00$ \\
\hline 3 & $\begin{array}{c}2 F E C_{H C G} \text { sub-cohorts } \\
1 \pi_{C L I N} \text { sub-cohort } \\
\text { (Model } 0)\end{array}$ & $\begin{array}{c}3 F E C_{H C G} \text { sub-cohorts } \\
3 \pi_{C L I N} \text { sub-cohorts } \\
\text { (Model } 3)\end{array}$ & 4 & $0.30,0.99$ & $1.49,0.83$ & $0.64,0.96$ \\
\hline 4 & $\begin{array}{c}\gamma=0 \\
\text { (Model 4) }\end{array}$ & $\begin{array}{c}\gamma \neq 0 \\
\text { (Model 0) }\end{array}$ & 1 & $34.3,5 \times 10^{-9}$ & $1.64,0.20$ & $42.8,6 \times 10^{-11}$ \\
\hline
\end{tabular}

Table 3. Estimates of conditional probabilities for different stages of the reproductive process for reproductively normal subjects. Estimates of hCG $\left(F E C_{H C G}\right)$ and clinical $\left(F E C_{C L I N}\right)$ fecundabilities and $\pi_{C L I N}$ are derived from three hCG pregnancy studies as described in the text. $\pi_{L B}$ is calculated from published values in Wilcox ${ }^{6}$, Zinaman ${ }^{7}$ and Wang ${ }^{8}$ study reports. Estimates of fertilised egg loss up to implantation, clinical recognition and birth are provided, based on three scenarios: (i) high implantation probability ( $\pi_{H C G}=90 \%$ ); (ii) equal implantation and fertilisation probabilities $\left(\pi_{\text {FERT }}=\pi_{\text {HCG }}\right)$; (iii) high fertilisation probability $\left(\pi_{\text {FERT }}=90 \%\right)$. The probability of sperm-ovum-co-localisation $\left(\pi_{\text {SOC }}\right)$ was assumed to be 0.80 .

\begin{tabular}{|c|c|c|c|c|c|c|c|c|c|}
\hline Derived Fecundabilities and Conditional & \multicolumn{3}{|c|}{ Wilcox (1988) } & \multicolumn{3}{|c|}{ Zinaman (1996) } & \multicolumn{3}{|c|}{ Wang (2003) } \\
\hline $\begin{array}{l}F E C_{H C G} \\
F E C_{C L I N} \\
\pi_{C L I N} \\
\pi_{L B}\end{array}$ & \multicolumn{3}{|c|}{$\begin{array}{l}0.432 \\
0.339 \\
0.783 \\
0.877\end{array}$} & \multicolumn{3}{|c|}{$\begin{array}{l}0.381 \\
0.333 \\
0.875 \\
0.790\end{array}$} & \multicolumn{3}{|c|}{$\begin{array}{l}0.462 \\
0.349 \\
0.754 \\
0.871\end{array}$} \\
\hline$\%$ loss from implantation to live birth & \multicolumn{3}{|c|}{31.3} & \multicolumn{3}{|c|}{30.9} & \multicolumn{3}{|c|}{34.2} \\
\hline $\begin{array}{l}\text { If } \pi_{\text {SOC }}=0.80 \text {, then } \pi_{F E R T} \times \pi_{H C G}= \\
\text { If } \pi_{F E R T}=\pi_{H C G} \text {, then } \pi_{F E R T}=\pi_{H C G}= \\
\text { If } \pi_{F E R T}=0.90, \text { then } \pi_{H C G}= \\
\text { If } \pi_{H C G}=0.90, \text { then } \pi_{F E R T}=\end{array}$ & \multicolumn{3}{|c|}{$\begin{array}{l}0.540 \\
0.735\end{array}$} & \multicolumn{3}{|c|}{$\begin{array}{l}0.476 \\
0.690\end{array}$} & \multicolumn{3}{|c|}{$\begin{array}{l}0.578 \\
0.760\end{array}$} \\
\hline Estimated losses of fertilised eggs when... & $\begin{array}{c}\pi_{H C G} \\
= \\
0.90\end{array}$ & $\begin{array}{c}\pi_{\text {FERT }} \\
= \\
\pi_{\mathrm{HCG}}\end{array}$ & $\begin{array}{c}\pi_{\text {FERT }} \\
= \\
0.90\end{array}$ & $\begin{array}{c}\pi_{H C G} \\
=\overline{=} \\
0.90\end{array}$ & $\begin{array}{c}\pi_{\text {FERT }} \\
= \\
\pi_{\text {HCG }}\end{array}$ & $\begin{array}{c}\pi_{\text {FERT }} \\
= \\
0.90\end{array}$ & $\begin{array}{c}\pi_{H C G} \\
== \\
0.90\end{array}$ & $\begin{array}{c}\pi_{\text {FERT }} \\
= \\
\pi_{\text {HCG }}\end{array}$ & $\begin{array}{c}\pi_{\text {FERT }} \\
= \\
0.90\end{array}$ \\
\hline $\begin{array}{l}\% \text { loss before implantation } \\
\% \text { loss before clinical recognition } \\
\% \text { loss before live birth }\end{array}$ & $\begin{array}{l}10.0 \\
29.5 \\
38.2\end{array}$ & $\begin{array}{l}26.5 \\
42.4 \\
49.5\end{array}$ & $\begin{array}{l}40.0 \\
53.0 \\
58.7\end{array}$ & $\begin{array}{l}10.0 \\
21.3 \\
37.8\end{array}$ & $\begin{array}{l}31.0 \\
39.6 \\
52.3\end{array}$ & $\begin{array}{l}47.1 \\
53.7 \\
63.4\end{array}$ & $\begin{array}{l}10.0 \\
32.1 \\
40.8\end{array}$ & $\begin{array}{l}24.0 \\
42.7 \\
50.0\end{array}$ & $\begin{array}{l}35.8 \\
51.6 \\
57.8\end{array}$ \\
\hline
\end{tabular}



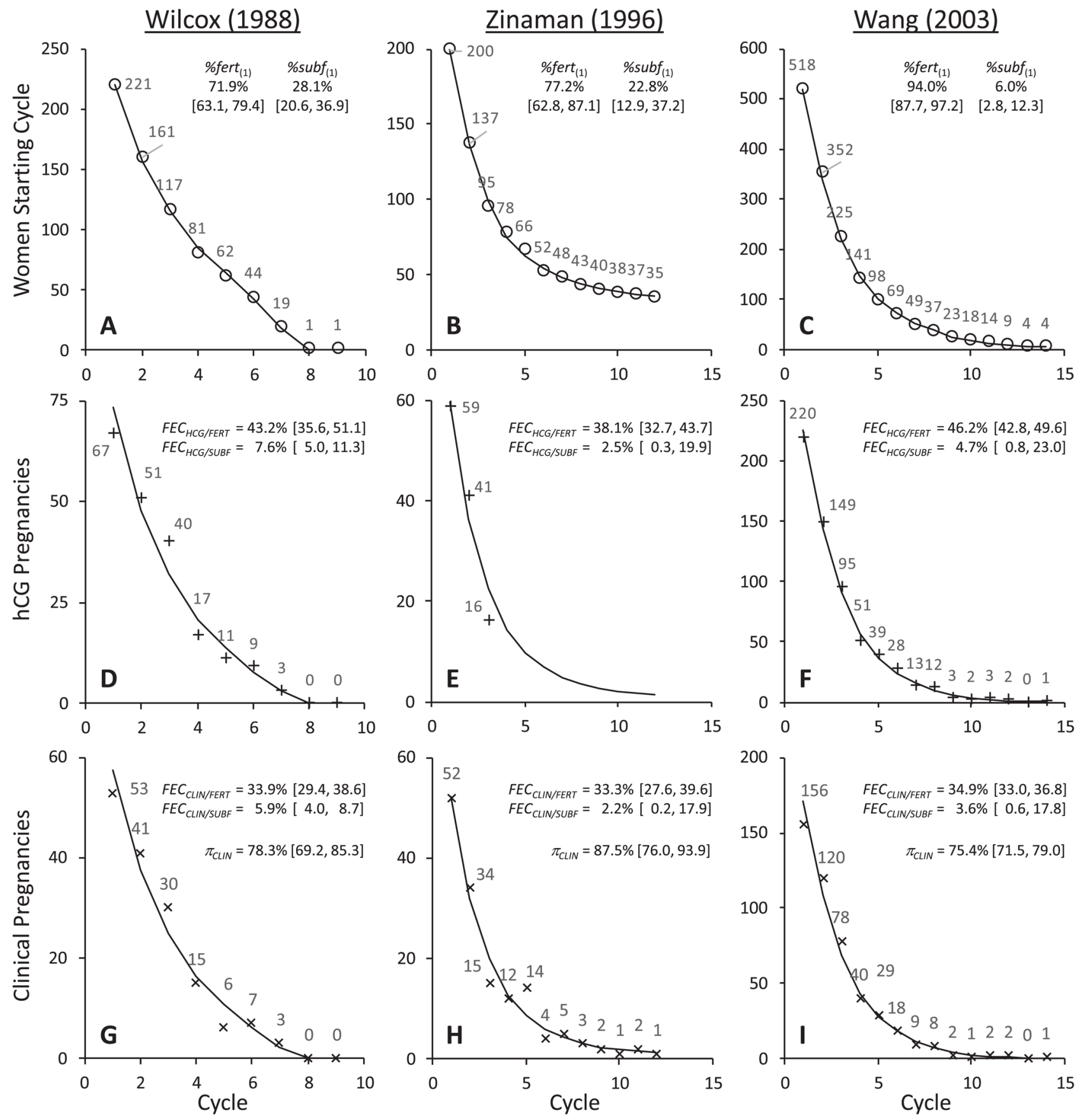

Figure 1. Graphical representation of data and best fit models for Wilcox (A, D, G), Zinaman (B, E, H) and Wang (C, F, I) studies. Each panel shows the data value from the study for each point $(\bigcirc=$ women starting cycle; $+=$ hCG pregnancies; $\times=$ clinical pregnancies). The line indicates the best fit models as defined in Table 1. Parameter estimates and [95\% confidence intervals] from these models are also shown. 
and so the original report $\operatorname{data}^{6}$ have been used. In Wilcox and Wang, for each study cycle, the number of (i) women starting each cycle, (ii) hCG pregnancies, and (iii) clinical pregnancies were recorded. The number of women who finished the study without becoming clinically pregnant and the number of women who dropped out at the end of each cycle were also reported. Women who conceived an hCG positive pregnancy but not a clinical pregnancy in a cycle continued in the study. Wilcox reported data for a maximum of nine cycles per subject and Wang for 14. The Zinaman study was similar, except that hCG data were obtained for only the first three study cycles. In the subsequent nine cycles only clinical pregnancy was recorded. Also, only the first pregnancy, whether hCG or clinical was reported.

Observed data were modelled to estimate the following parameters: (1) \% fert $_{\text {(1) }}=$ the percentage of fertile women in the starting cohort; (2) $F E C_{H C G}=$ the probability of conceiving an hCG pregnancy per cycle; (3) $F E C_{C L I N}$ the probability of becoming clinically pregnant per cycle. Alternative parameterisation allowed the probability of an hCG pregnancy progressing to a clinical pregnancy $\left(\pi_{C L I N}\right)$ to also be determined. The percentage of sub-fertile women in the starting cohort was $\%$ subf $_{(1)}=100 \%-\%$ fert $_{(1)} . F E C_{H C G}, F E C_{\text {CLIN }}$ and $\pi_{\text {CLIN }}$ were determined for both fertile and sub-fertile sub-cohorts. The following expressions define the relationship between the parameters and the modelled estimates.

$$
\begin{aligned}
& N_{F E R T(\#)}=N_{(\#)} \times \%_{\text {fert }} \\
& N_{S U B F(\#)}=N_{(\#)}-N_{F E R T(\#)} \\
& P R E G_{H C G / F E R T(\#)}=N_{F E R T(\#)} \times F E C_{H C G / F E R T} \\
& P R E G_{\text {CLIN/FERT(\#) }}=N_{F E R T(\#)} \times F E C_{H C G / F E R T} \times \pi_{C L I N / F E R T} \\
& F E C_{\text {CLINFERT }}=F E C_{H C G / F E R T} \times \pi_{\text {CLIN/FERT }} \\
& P R E G_{\text {CLIN(\#) }}=P R E G_{\text {CLINFERT(\#) }}+P R E G_{\text {CLINSUBF(\#) }} \\
& N_{(\#+1)}=N_{(\#)}-P R E G_{C L I N(\#)}-F I N_{(\#)}-D R O P_{(\#)} \\
& \%_{\text {fert }}^{(\#+1)}=\left(N_{\text {FERT(\#) }}-P R E G_{\text {CLINFERT }(\#)}\right) \div\left(N_{(\#)}-P R E G_{\text {CLIN }(\#)}\right) \\
& N O N P R E G_{(\#)}=\left[N_{F E R T(1)} \times\left(1-F E C_{\text {CLINFERT }}\right)^{\#}\right]+\left[N_{\text {SUBF }(1)} \times\left(1-F E C_{\text {CLINSUBF }}\right)^{\#}\right]
\end{aligned}
$$

Where: $N_{\text {(\#) }}$ is the number of women starting cycle \# (for cycle 1 , $N_{(1)}$ was fixed for each set of study data; Wilcox $=221$; Zinaman = 200; Wang = 518); $N_{F E R T(\#)}$ and $N_{S U B F(\#)}$ are the modelled number of fertile and sub-fertile women starting cycle \#; PREG $G_{H C G / F E R T(\#)}$ and $P R E G_{\text {CLIN/FERT(\#) }}$ are predicted numbers of hCG and clinical pregnancies in fertile women in cycle \# (and analogously for sub-fertile women); $F I N_{(\#)}$ is the number of women who finished the study without becoming clinically pregnant in cycle \#; $D R O P_{(\#)}$ is the number of women who withdrew from the study at the end of cycle \#; \% fert $_{(\#)}$ is the percentage of women starting cycle \# who were fertile (and analogously for sub-fertile women); NONPREG is the number of non-pregnant women after \# cycles (equation (9) was only used to incorporate 14 non-pregnant women after 24 months into the Wilcox data model). Model expansion to allow three fertility sub-cohorts and contraction to a single fertility sub-cohort enabled hypotheses about parameters and sub-cohorts to be statistically evaluated.

All probabilities and percentages were estimated as logits (base $10)$. Residual unexplained variance $(R U V)$ was modelled as a function of predicted values (PRED) as follows:

$$
R U V=\sigma^{2} \times P R E D^{\gamma}
$$

...where $\sigma$ is an estimated parameter defining residual error and $\gamma$ a coefficient defining the relationship between the dependent variables and PRED. When $\gamma=0$, the residual model is homoscedastic. When $\gamma=2$, the residual coefficient of variation is a constant.

Data were analysed with NONMEM 7.3.0 (Icon PLC, Dublin, Eire) and implemented using Wings for NONMEM (http://wfn. sourceforge.net/). Parameters were estimated using a maximum likelihood algorithm (First Order Conditional Estimate with Interaction) and standard errors derived using the inverse Hessian (MATRIX = R). The objective function in NONMEM is the Extended Least Squares $(E L S)^{27}$. Statistical hypotheses of nested models (Table 2) were tested using likelihood ratio tests (LRT). Control and data files are available online. Control files are named from the study and the model, e.g., WANG0.ctl is the control file for Model 0 applied to the Wang study data.

\section{Results}

Figure 1 shows the original data values and the fitted models plotted by cycle. Parameter estimates are also shown and output from the models is given in Table 1 . These models incorporate discrete fertile and sub-fertile sub-cohorts with differing $F E C_{H C G}$ but common $\pi_{\text {CLIN }}$ values. Statistical comparison of alternative models strongly indicated that reducing the dimensionality of the model to a single $F E C_{H C G}$ value substantially reduced its quality (Table 2, Hypothesis 1), whereas expanding the model to allow for three different $F E C_{H C G}$ values did not improve the quality of the model (Table 2, Hypothesis 2). These statistical results indicate that the data are consistent with bi-modal study populations comprising two distinct fertility sub-cohorts. There was no statistical indication that $\pi_{C L I N}$ differed between these sub-cohorts (Table 2, Hypothesis 3). Evidence for heteroscedasticity in the residual error was strong for the Wilcox and Wang studies, and weak for the Zinaman study (Table 2, Hypothesis 4).

Figure 2 illustrates the estimated parameter values. Notwithstanding the differences between the studies, there is considerable agreement in the estimates. One noteworthy difference is in the proportion of sub-fertile women. This was low $(6.0 \%)$ in the Wang study compared to the other two which were approximately $25 \%$. Zinaman et al. commented on the high proportion of apparently infertile women in their study despite their efforts during recruitment ${ }^{7}$. The estimate of $22.8 \%$ sub-fertile women is consistent with their estimate of $18 \%$ infertility, bearing in mind that sub-fertile women may conceive, albeit with a lower probability. The Wang study was conducted in young Chinese women and had the highest $F E C_{\text {HCG/FERT }}(46.2 \%)$ and lowest $\pi_{\text {CLIN }}(75.4 \%)$ values. This may reflect the Bayesian methodology used to detect hCG 

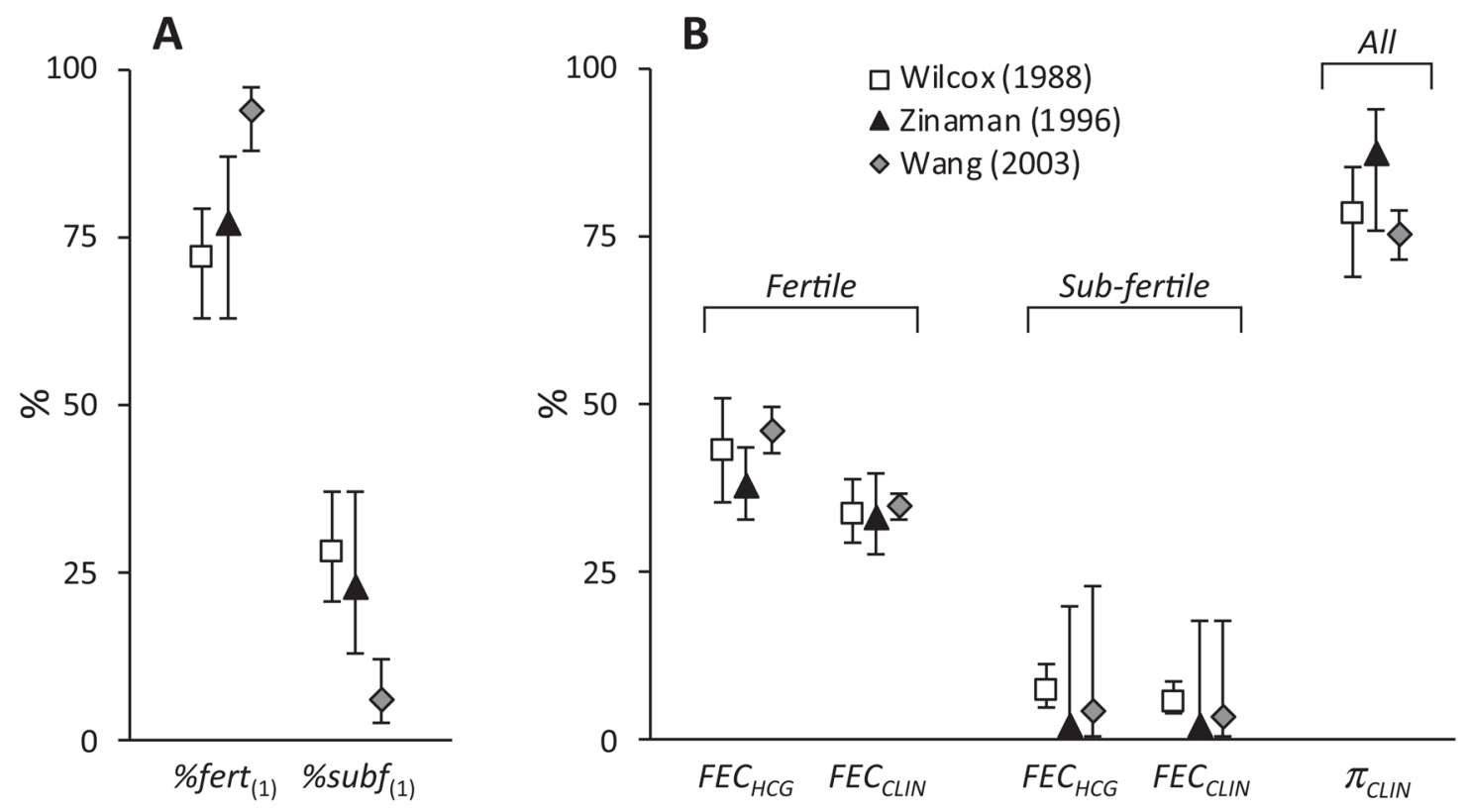

Figure 2. Parameter estimates for fertile and sub-fertile sub-cohorts and associated fecundability values. Values are shown for Wilcox $(\square)$, Zinaman $(\boldsymbol{\Delta})$ and Wang $(\diamond)$ studies. Panel A shows the proportions in the starting cohorts modelled as fertile or sub-fertile (\% fert ${ }_{(1)}$ \& $\%$ subf $\left._{(1)}\right)$. Panel B shows the hCG $\left(F E C_{H C G}\right)$ and clinical $\left(F E C_{C L I N}\right)$ fecundabilities and the probability of hCG pregnancies progressing to clinical pregnancies $\left(\pi_{C L I N}\right)$. Values are derived from modelled parameter estimates (Table 1 ) and error bars indicate 95\% confidence intervals.

positive cycles, the identification of DDT (dichlorodiphenyltrichloroethane), present at unusually high levels in this group $^{28}$, as a positive predictor of pre-clinical pregnancy $\operatorname{loss}^{29}$, or even a higher incidence of gestational tropho-blastic disease in Asian women ${ }^{30}$.

The analysis also indicates that fewer hCG pregnancies in the Zinaman study (12.5\%) failed to progress to clinical recognition, compared to either the Wilcox $(21.7 \%)$ or Wang (24.6\%) studies. This may reflect differences in methodology for detecting hCG, the fact that they made fewer hCG measurements or differences in the definition of clinical pregnancy. Wilcox and Wang defined clinical pregnancy as those that lasted for up to 6 weeks after the last menstrual period ${ }^{6,8,17,26}$. In Zinaman, clinical pregnancy was determined following serum testing if a woman's anticipated menses was just one day late ${ }^{7}$. Hence, the window for pre-clinical embryo loss was approximately $1-4$ weeks post-fertilisation for Wilcox and Wang and 1-2 weeks for Zinaman. This different definition of clinical pregnancy would not only contribute to the higher $\pi_{\text {CUN }}$ value from Zinaman but also the increased clinical loss of $21.0 \%$ compared to $12-13 \%$ observed by Wilcox and Wang.

Quantifying the outcome of clinical pregnancies is relatively straightforward. Excluding those lost to follow-up and induced abortions, the probability of a clinical pregnancy progressing to a live birth $\left(\pi_{L B}\right)$ was: Wilcox, 87.7\% (136/155); Zinaman, $79.0 \%$ (79/100); and Wang, 87.1\% (373/428). Combining these values with the modelled $\pi_{C L I N}$ provides an estimate for embryo loss from implantation to live birth of $31.3 \%$ (Wilcox), 30.9\% (Zinaman) and $34.2 \%$ (Wang) (Table 3).

Estimating embryo loss prior to hCG detection is less straightforward. For sub-fertile participants, it is impossible to know why they struggled to become pregnant: there are many causes of subfertility $^{31}$. However, for normally fertile women the modelled hCG fecundability values can be used to put limits on fertilisation $\left(\pi_{F E R T}\right)$ and implantation $\left(\pi_{H C G}\right)$ conditional probabilities. As noted above, fecundability is the product of the conditional probabilities of success for each stage of the reproductive cycle. Hence for Wang:

$$
F E C_{H C G}=\pi_{S O C} \times \pi_{F E R T} \times \pi_{H C G}=0.462
$$

Since probabilities cannot be greater than 1 , the lowest possible value for $\pi_{H C G}$ must be 0.462 , indicating a maximum possible loss from fertilisation up to implantation in these women of $53.8 \%$. However, it is unlikely that all other probabilities equal 1 . Sperm-ovum-co-localisation is dependent on both behavioural and biological factors. As previously noted, the analyses of Barrett \& Marshall $^{22,32}$ and Schwartz ${ }^{23}$ show that daily intercourse is more reproductively effective than alternate day intercourse. Hence, at coital frequencies less than once per day, $\pi_{S O C}$ must be less than 1 . Specifically, a reduction of fecundability from 0.49 with daily to 0.39 for alternate day intercourse ${ }^{23}$ points towards a reduction in $\pi_{\text {SOC }}$ of approximately $20 \%$. Volunteers in these hCG studies wished to become pregnant and were undoubtedly aware of the importance 
of well-timed intercourse. However, they were not required to have daily intercourse and it is likely that in some of the 3,137 cycles intercourse was not always ideally timed. Indeed, in 360/625 cycles in the Wilcox study, intercourse occurred from zero to two times during the 6 days before ovulation, and intercourse occurred on only $40 \%$ of the 6 pre-ovulatory days in 625 cycles $^{17}$. It seems likely therefore that $\pi_{S O C}$ and hence fecundability were not maximised in these studies.

Furthermore, not all cycles are ovulatory. Leridon suggested that levels of anovulation lie between 5 and $15 \%$. Among normal healthy women, the incidence of anovulation ranged from $5.5-12.8 \%$ depending on the detection method used ${ }^{34}$. Therefore, considering behavioural and biological factors together, it seems reasonable to suppose that $\pi_{S O C}<1$.

It also seems unlikely that either fertilisation or implantation probabilities equal 1 . Hence, Table 3 shows derived values for $\pi_{F E R T}$ and $\pi_{H C G}$ assuming that $\pi_{S O C}=0.80$, and under conditions where: (i) $\pi_{F E R T}=0.90$; (ii) $\pi_{F E R T}=\pi_{H C G}$; and (iii) $\pi_{H C G}=0.90$. Based on this analysis, a plausible range for total embryo loss from fertilisation to birth is $40-60 \%$. This is consistent with estimates from both older $^{35}$ and more recent ${ }^{36}$ text books. Even with the wide range of mathematically possible outcomes, it is likely that estimates of $90 \%^{20}, 83 \%^{37}, 80-85 \%^{38}, 78 \%^{1}, 76 \%^{2}$ and $70 \%^{10,12}$ total human embryonic loss are excessive.

\section{Dataset 1. Raw data Wilcox et al. study}

http://dx.doi.org/10.5256/f1000research.9479.d133951

One data file and six control files are provided. The data file is saved as csv. and the control files can be read with any simple text editor. The readme file provides a data legend.

\section{Dataset 2. Raw data Zinaman et al. study}

http://dx.doi.org/10.5256/f1000research.9479.d133952

One data file and six control files are provided. The data file is saved as csv. and the control files can be read with any simple text editor. The readme files provides a data legend.

\section{Dataset 3. Raw data Wang et al. study}

http://dx.doi.org/10.5256/f1000research.9479.d133953

The data file and six control files are provided. The data file is saved as csv. and the control files can be read with any simple text editor. The readme file provides a data legend.

\section{Discussion}

In 1980, Schwartz wrote that Barrett \& Marshall's estimate of fecundability of 0.68 for daily intercourse "seems to be high". It implies an absolute maximum limit of embryo mortality of $32 \%$.
Schwartz contrasted this with Leridon's estimate of $44 \%$ embryo loss in the first 6 weeks following fertilisation ${ }^{3}$. However, Leridon's estimates for early intrauterine mortality are substantially dependent on data and analysis from Hertig ${ }^{4,5}$, which are themselves of questionable precision ${ }^{2,13,39}$. Widespread pessimism about human reproductive efficiency may have become a self-fulfilling prophecy in the absence of relevant good quality data.

Nevertheless, Schwartz's analysis is a useful improvement on that of Barrett \& Marshall and points clearly to the presence of infertile or non-viable cycles. The challenge arises in assigning a mechanistic cause for this "non-viability". Previous reports draw attention to the difficulty of teasing apart distinct components, e.g., egg viability versus uterine receptivity ${ }^{24}$, or male and female factors ${ }^{15}$, and alternative modelling approaches will yield "different interpretations of the parameters related to cycle viability"15. The advantage of the present models is that the unit of analysis remains the cycle, i.e., fecundability, but the heterogeneity of the population is also acknowledged and explicitly incorporated. The model for estimating embryo loss also accommodates other plausible mechanisms for reproductive failure, rather that accrediting all unaccounted reproductive inefficiency to pre-implantation embryo mortality. Although the model does not provide a definitive answer, it does offer plausible limits within which the answer may lie.

The results of this analysis offer a statistically clear picture of bimodal study populations comprising couples with two discrete levels of fertility. This dichotomous division of the study populations is arguably artificial: it is unlikely to capture all the quantitative subtlety that subsists in the original data. Nevertheless, expanding the model to three levels does not improve this picture and the published data do not support a model of uni-modal, albeit varied, fecundability. Put simply, there was a significant proportion of couples in these studies who were, for unknowable reasons, infertile or clearly sub-fertile. Incorporation of data derived from such couples in calculations to determine normal fecundability will therefore result in biased estimates. By analytically separating the study population into reproductively normal and sub-fertile subcohorts, more accurate estimates for normal reproductive function and embryo mortality have been obtained. Such estimates apply primarily to the specific study populations, which are not necessarily fully representative of a general population. The extrapolation of quantitative conclusions into other contexts and circumstances must always be done with appropriate caution.

The analysis presented here cannot be satisfactorily completed owing, in part, to a lack of data on fertilisation success rates in vivo ${ }^{40,41}$. Consequently, the range for pre-implantation loss, at approximately $10-40 \%$, is wide, although inclusive of Hertig's pre-implantation loss estimate of $30 \%$, Despite the imperfections and weaknesses in the available data, it is apparent that plausible values for embryo mortality are considerably less than some figures published in the scientific literature. It is concluded that a plausible 
range for natural human embryo mortality from fertilisation to live birth in normal healthy women is approximately $40-60 \%$.

\section{Data availability}

F1000Research: Dataset 1. Raw data Wilcox et al. study, 10.5256/ f1000research.9479.d133951 $1^{42}$

F1000Research: Dataset 2. Raw data Zinaman et al. study, 10.5256/ f1000research.9479.d133952 $2^{43}$

F1000Research: Dataset 3. Raw data Wang et al. study, 10.5256/ f1000research.9479.d133953 ${ }^{44}$
Competing interests

No competing interests were disclosed.

Grant information

The author(s) declared that no grants were involved in supporting this work.

\section{Acknowledgements}

Thanks are due to Professor David Paton for providing helpful comments and suggestions during the writing of this paper.
1. Roberts CJ, Lowe CR: Where have all the conceptions gone? Lancet. 1975; 305(7905): 498-9.

Publisher Full Text

2. Boklage CE: Survival probability of human conceptions from fertilization to term. Int J Fertil. 1990; 35(2): 75, 79-80, 81-94.

PubMed Abstract

3. Leridon $\mathrm{H}$ : Intrauterine Mortality. Human Fertility: The Basic Components. Chicago: The University of Chicago Press; 1977; 48-81.

Reference Source

4. Hertig AT, Rock J, Adams EC, et al:: Thirty-four fertilized human ova, good, bad and indifferent, recovered from 210 women of known fertility; a study of biologic wastage in early human pregnancy. Pediatr. 1959; 23(1 Part 2): 202-11. PubMed Abstract

5. Hertig AT: The Overall Problem in Man. In: Benirschke K, editor. Comparative Aspects of Reproductive Failure: An International Conference at Dartmouth Medical School. Berlin: Springer Verlag; 1967; 11-41. Publisher Full Text

6. Wilcox AJ, Weinberg CR, O'Connor JF, et al.: Incidence of early loss of pregnancy. N Engl J Med. 1988; 319(4): 189-94. PubMed Abstract | Publisher Full Text

7. Zinaman MJ, Clegg ED, Brown CC, et al: Estimates of human fertility and pregnancy loss. Fertil Steril. 1996; 65(3): 503-9. PubMed Abstract | Publisher Full Text

8. Wang $\mathrm{X}$, Chen $\mathrm{C}$, Wang $\mathrm{L}$, et al:: Conception, early pregnancy loss, and time to clinical pregnancy: a population-based prospective study. Fertil Steril. 2003; 79(3): 577-84.

PubMed Abstract | Publisher Full Text

9. Cole LA: hCG, the wonder of today's science. Reprod Biol Endocrinol. 2012; 10: 24. PubMed Abstract | Publisher Full Text | Free Full Text

10. Chard T: Frequency of implantation and early pregnancy loss in natural cycles. Baillieres Clin Obstet Gynaecol. 1991; 5(1): 179-89.

PubMed Abstract | Publisher Full Text

11. Wilcox AJ, Weinberg CR, Wehmann RE, et al:: Measuring early pregnancy loss: laboratory and field methods. Fertil Steril. 1985; 44(3): 366-74. PubMed Abstract | Publisher Full Text

12. Macklon NS, Geraedts JP, Fauser BC: Conception to ongoing pregnancy: the 'black box' of early pregnancy loss. Hum Reprod Update. 2002; 8(4): 333-43. PubMed Abstract | Publisher Full Text

13. Biggers JD: Risks of In Vitro Fertilization and Embryo Transfer in Humans. In: Crosignani PG, Rubin BL, editors. In Vitro Fertilization and Embryo Transfer. London: Academic Press, 1983; 393-410.

14. Benagiano G, Farris M, Grudzinskas G: Fate of fertilized human oocytes. Reprod Biomed Online. 2010; 21(6): 732-41. PubMed Abstract | Publisher Full Tex

15. Zhou H, Weinberg $\mathrm{CR}$, Wilcox $\mathrm{AJ}$, et al:: A random-effects model for cycle viability in fertility studies. J Am Stat Assoc. 1996; 91(436): 1,413-22. PubMed Abstract | Publisher Full Text

16. Asher GW: Reproductive cycles of deer. Anim Reprod Sci. 2011; 124(3-4): $170-5$.

PubMed Abstract | Publisher Full Text

17. Wilcox AJ, Weinberg CR, Baird DD: Timing of sexual intercourse in relation to ovulation. Effects on the probability of conception, survival of the pregnancy, and sex of the baby. N Engl J Med. 1995; 333(23): 1517-21.

PubMed Abstract | Publisher Full Text

18. Drife JO: What proportion of pregnancies are spontaneously aborted? Brit Med J 1983; 286(6361): 294.

Reference Source

19. Braude PR, Johnson MH: The Embryo in Contemporary Medical Science. In: Dunstan GR, editor. The Human Embryo: Aristotle and the Arabic and European Traditions. Exeter: University of Exeter Press; 1990; 208-21.

20. Opitz JM: Human Development - The Long and the Short of it. In: Furton EJ, Mitchell LA, editors. What is Man O Lord? The Human Person in a Biotech Age, Eighteenth Workshop for Bishops. Boston, MA: The National Catholic Bioethics Center; 2002; 131-53.

21. Leridon H: Fecundability. Human Fertility: The Basic Components. Chicago: The University of Chicago Press; 1977 ; 22-47. Reference Source

22. Barrett JC, Marshall $\mathrm{J}$ : The risk of conception on different days of the menstrual cycle. Popul Stud (Camb). 1969; 23(3): 455-61. PubMed Abstract | Publisher Full Text

23. Schwartz D, Macdonald PD, Heuchel V: Fecundability, coital frequency and the viability of Ova. Popul Stud (Camb). 1980; 34(2): 397-400. PubMed Abstract | Publisher Full Text

24. Weinberg $\mathrm{CR}$, Gladen $\mathrm{BC}$, Wilcox AJ: Models relating the timing of intercourse to the probability of conception and the sex of the baby. Biometrics. 1994; 50(2): 358-67.

PubMed Abstract | Publisher Full Text

25. Zhou $\mathrm{H}$, Weinberg $\mathrm{CR}$ : Potential for bias in estimating human fecundability parameters: a comparison of statistical models. Stat Med. 1999; 18(4): 411-22. PubMed Abstract | Publisher Full Text

26. Wilcox AJ, Weinberg CR, Baird DD: Risk factors for early pregnancy loss. Epidemiology. 1990; 1(5): 382-5. PubMed Abstract

27. Sheiner LB, Beal SL: Pharmacokinetic parameter estimates from several leas squares procedures: superiority of extended least squares. $J$ Pharmacokinet Biopharm. 1985; 13(2): 185-201. PubMed Abstract | Publisher Full Tex

28. Longnecker MP: Invited Commentary: Why DDT matters now. Am J Epidemiol. 2005; 162(8): 726-8. PubMed Abstract | Publisher Full Text

29. Venners SA, Korrick S, Xu X, et al.: Preconception serum DDT and pregnancy loss: a prospective study using a biomarker of pregnancy. Am J Epidemiol. 2005; 162(8): 709-16. PubMed Abstract | Publisher Full Text

30. Tham BW, Everard JE, Tidy JA, et al.: Gestational trophoblastic disease in the Asian population of Northern England and North Wales. Br J Obstet Gynaecol. 2003; 110(6): 555-9. PubMed Abstract | Publisher Full Text

31. Edwards RG: Introduction. Conception in the Human Female. London: Academic Press, 1980; 1-22.

32. Barrett JC: Fecundability and coital frequency. Popul Stud (Camb). 1971; 25(2): 309-13.

PubMed Abstract | Publisher Full Tex 
33. Leridon H: The Physiological Basis. Human Fertility: The Basic Components. Chicago: The University of Chicago Press; 1977; 5-16. Reference Source

34. Lynch KE, Mumford SL, Schliep KC, et al:: Assessment of anovulation in eumenorrheic women: comparison of ovulation detection algorithms. Fertil Steril. 2014; 102(2): 511-518.e2. PubMed Abstract | Publisher Full Text | Free Full Text

35. Edwards RG: Sexuality and Coitus. Conception in the Human Female. London Academic Press; 1980; 525-72 at 561.

36. Jones RE, Lopez KH: Pregnancy. Human Reproductive Biology. 4th ed. Amsterdam: Elsevier, 2014; 175-204. Publisher Full Text

37. Harris J: Stem cells, sex and procreation. Camb Q Healthc Ethics. 2003; 12(4) 353-71

PubMed Abstract | Publisher Full Text

38. Johnson MH, Everitt BJ: Chapter 15: Fertility. Essential Reproduction. 5th ed. Oxford: Wiley-Blackwell; 2000; 251-74.
39. Potts M, Diggory P, Peel J: Spontaneous Abortion. Abortion. Cambridge: Cambridge University Press, 1977; 45-64.

40. Short RV: When a conception fails to become a pregnancy. Ciba Found Symp. 1978; (64): 377-94.

PubMed Abstract | Publisher Full Text

41. Kline J, Stein Z, Susser M: Conception and Reproductive Loss: Probabilities. Conception to Birth. Epidemiology of Prenatal Development. New York: OUP, 1989; $43-68$.

42. Jarvis GE: Dataset 1 in: Estimating Limits for Natural Human Embryo Mortality. F1000Research. 2016. Data Source

43. Jarvis GE: Dataset 2 in: Estimating Limits for Natural Human Embryo Mortality. F1000Research. 2016. Data Source

44. Jarvis GE: Dataset 3 in: Estimating Limits for Natural Human Embryo Mortality. F1000Research. 2016. Data Source 


\title{
Open Peer Review
}

\section{Current Peer Review Status:}

\section{Version 1}

Reviewer Report 03 October 2016

https://doi.org/10.5256/f1000research.10209.r16765

(C) 2016 Trounson A. This is an open access peer review report distributed under the terms of the Creative Commons Attribution License, which permits unrestricted use, distribution, and reproduction in any medium, provided the original work is properly cited.

\begin{abstract}
Alan 0. Trounson
Hudson Institute for Medical Research, Monash University, Clayton, VIC, Australia

This is a well thought out analysis of the data available on human pregnancy wastage. The conclusions are valid from the data explored but the major variant of failed fertilization and very early embryo loss cannot be estimated. Failed fertilization will always be an unknown in such studies but early embryo loss can be estimated from the large amount of IVF data published on embryo survival to the blastocyst stage (day 5-7). However, the vast bulk of this data comes from superovulated patients and this may not represent embryo loss in the natural ovulatory cycle. This data suggests that only $30 \%$ of conceptions end up as live babies at delivery (Macklon et al., 2002)

Indeed embryonic arrest before day 5 can be attributed to whole chromosome abnormalities in more than half of human embryos (McCoy et al., 2015). The embryonic losses due to mitotic and meiotic support the high embryonic wastage in human reproduction. It is a pity the authors didn't include this genetic data in support of their hypothesis
\end{abstract}

\section{References}

1. Macklon NS, Geraedts JP, Fauser BC: Conception to ongoing pregnancy: the 'black box' of early pregnancy loss. Hum Reprod Update. 8 (4): 333-43 PubMed Abstract

2. McCoy RC, Demko ZP, Ryan A, Banjevic M, et al.: Evidence of Selection against Complex MitoticOrigin Aneuploidy during Preimplantation Development.PLoS Genet. 2015; 11 (10): e1005601

PubMed Abstract | Publisher Full Text

Competing Interests: No competing interests were disclosed.

I confirm that I have read this submission and believe that I have an appropriate level of expertise to confirm that it is of an acceptable scientific standard.

Author Response 29 Nov 2016

Gavin Jarvis, University of Sunderland, UK 
I would like to thank Professor Trounson for his remarks ${ }^{1}$. I respond to his comments as follows:

1. Use of IVF data: The study was intentionally restricted to the analysis of hCG data from a natural reproductive context, and from the three studies in particular ${ }^{2-4}$. As Prof. Trounson indicates, data from IVF may not be representative of natural cycles. Extrapolation of conclusions from a specific to a wider or different context should always be done with caution (see review by Prof. Senn ${ }^{5}$ ). The use of IVF data to inform our understanding of natural reproduction can be particularly difficult, as I note elsewhere ${ }^{6}$.

2. Macklon et al., 20027: This is a well-known and frequently cited review. I discuss the referenced value of $30 \%$ elsewhere ${ }^{6}$. However, contrary to what Prof. Trounson seems to imply, it is neither a summary of nor an extrapolation from IVF data. It is part of Macklon's "overview of the outcome of spontaneous human pregnancy", and is copied directly from an earlier review on the "frequency of implantation and early pregnancy loss in natural cycles" by Prof. Tim Chard ${ }^{8}$. Macklon is explicit in stating that the conditions from which in vitro data are obtained are "far from ideal" and "do not reflect the normal situation"7. He reviews several hCG studies concluding that many problems associated with these were addressed by Wilcox ${ }^{2}$ and subsequently Zinaman ${ }^{3}$. Surprisingly however, the numerical estimates in Macklon (including the $30 \%$ survival value) do not reflect the outcome from these two studies, as I explain elsewhere ${ }^{6}$.

3. McCoy et al., 20159: It is difficult to incorporate quantitative conclusions from McCoy into a model of natural human embryo loss. All McCoy's data are from IVF embryos and are susceptible to criticism regarding their accuracy as a description of natural reproduction. As he himself states: "specific rates of meiotic and mitotic error reported in this study are likely particular to the IVF population" and "studies also demonstrated that ovarian stimulation and IVF culture conditions can both influence rates of chromosome abnormalities"9. McCoy cites Macklon 7 as authority for a $70 \%$ loss of all conceptions in human reproduction. Moreover, he goes further by associating this loss specifically with "young, otherwise fertile couples" 9 .

McCoy also cites a published summary ${ }^{10}$ of Edmonds, $1982^{11}$, an early hCG study. Edmonds' data lie at one extreme of the pre-Wilcox studies, with $56.8 \%$ of hCG+ cycles failing prior to clinical recognition. By contrast, Walker, $1988^{12}$ reported no preclinical losses of hCG+ pregnancies. Neither Edmonds' nor Walker's estimates have been replicated since Wilcox, $1988^{2}$. Subsequent studies report a post-implantation, pre-clinical loss of approximately $20 \%{ }^{6}$. Elsewhere ${ }^{13}$, McCoy states that "Fewer than $\sim 30 \%$ of conceptions result in successful pregnancy", citing Wilcox. However, Wilcox ${ }^{2}$ reports that "The total rate of pregnancy loss after implantation, including clinically recognized spontaneous abortions, was 31\%".

Therefore, McCoy's conclusion that high levels of aneuploidy observed in IVF embryos can explain natural human embryo loss is not well-founded, since natural embryo loss is substantially lower than he claims. An alternative view is that the high level of aneuploidy observed in vitro is, at least in part, an artefact of the handling of human ova and the associated interventions of assisted reproductive technology, as 
suggested by Chard ("it is possible that at least some of the abnormalities are the result of the experimental procedures themselves" 8 ) and Braude ("Experiments in our laboratories have suggested that the in vitro handling of oocytes can produce chromosomal aberrations at alarmingly high frequencies"14). The critical question is how large is that part?

These issues are addressed in more detail elsewhere ${ }^{6}$.

\section{References:}

1. Trounson A: Referee Report For: Estimating limits for natural human embryo mortality [version 1; referees: 2 approved]. F1000Research 2016; 5: 2083.

2. Wilcox AJ, Weinberg CR, O'Connor JF, et al.: Incidence of early loss of pregnancy. $N$ EnglJ Med. 1988; 319(4): 189-94. PubMed PMID: 3393170.

3. Zinaman MJ, Clegg ED, Brown CC, et al.: Estimates of human fertility and pregnancy loss. Fertil Steril. 1996; 65(3): 503-9. PubMed PMID: 8774277. Epub 1996/03/01. eng.

4. Wang $X$, Chen $C$, Wang $L$, et al.: Conception, early pregnancy loss, and time to clinical pregnancy: a population-based prospective study. Fertil Steril. 2003; 79(3): 577-84. PubMed PMID: 12620443. Epub 2003/03/07. eng.

5. Senn SJ: Referee Report For: Estimating limits for natural human embryo mortality [version 1; referees: 2 approved]. F1000Research. 2016; 5: 2083.

6. Jarvis GE: Early embryo mortality in natural human reproduction: What the data say [version 1; referees: awaiting peer review]. F1000Research. 2016; 5: 2765.

7. Macklon NS, Geraedts JP, Fauser BC: Conception to ongoing pregnancy: the 'black box' of early pregnancy loss. Hum Reprod Update. 2002; 8(4): 333-43. PubMed PMID: 12206468. Epub 2002/09/11. eng.

8. Chard T: Frequency of implantation and early pregnancy loss in natural cycles. Baillieres Clin Obstet Gynaecol. 1991; 5(1): 179-89. PubMed PMID: 1855339. Epub 1991/03/01. eng.

9. McCoy RC, Demko ZP, Ryan A, et al.: Evidence of Selection against Complex MitoticOrigin Aneuploidy during Preimplantation Development. PLOS genetics. 2015; 11 (10): e1005601. PubMed PMID: 26491874. Pubmed Central PMCID: 4619652. Epub 2015/10/23. eng.

10. Edmonds DK, Lindsay KS, Miller JF, et al.: Early embryonic mortality in women. Obstetrical and Gynecological Survey. 1983; 38(7): 433-34. eng.

11. Edmonds DK, Lindsay KS, Miller JF, et al.: Early embryonic mortality in women. Fertil Steril. 1982; 38(4): 447-53. PubMed PMID: 7117572. Epub 1982/10/01. eng.

12. Walker EM, Lewis M, Cooper W, et al.: Occult biochemical pregnancy: fact or fiction? Br J Obstet Gynaecol. 1988; 95(7): 659-63. PubMed PMID: 3273753. Epub 1988/07/01. eng.

13. McCoy RC, Demko Z, Ryan A, et al.: Common variants spanning PLK4 are associated with mitotic-origin aneuploidy in human embryos. Science. 2015; 348(6231): 235-8. PubMed PMID: 25859044. Epub 2015/04/11. eng.

14. Braude PR, Johnson MH, Pickering SJ, et al. Mechanisms of Early Embryonic Loss In Vivo and In Vitro. In: Chapman. M, Grudzinskas G, Chard T, editors. The Embryo: Normal and Abnormal Development and Growth. London: Springer-Verlag; 1991. p. 1 10. 
Competing Interests: No competing interests were disclosed.

Reviewer Report 19 September 2016

https://doi.org/10.5256/f1000research.10209.r15931

(C) 2016 Senn S. This is an open access peer review report distributed under the terms of the Creative Commons Attribution License, which permits unrestricted use, distribution, and reproduction in any medium, provided the original work is properly cited.

\section{Stephen J. Senn}

Competence Center for Methodology and Statistics, Luxembourg Institute of Health, Strassen, Luxembourg

This is an interesting and generally well-written article. I am unfamiliar with the field of reproductive physiology and female fertility regulation and so cannot be described as an expert reviewer. However, I do have expertise in the field of statistics and modelling and felt to understand the issues much better having read this article and that is a tribute to its general clarity.

Nevertheless, at one or two points I felt the clarity could have been improved. The author is not always completely explicit on two points. The first is whether a conditional probability is being estimated (and if so conditional on what) and the second is the precise details of the mixed model being used.

Since readers will not necessarily be familiar with the software an author uses, and since the more complex the subject the more likely an algorithm will differ between packages, one of the inevitable problems in a field of this complexity are 1) that it is quite likely that readers will not be familiar with some details of implementation and 2) results might differ somewhat from package to package. The author has used NONMEM, a package that is popular in nonlinear mixed effect modelling in pharmacokinetics but less well-known in other fields. This is a limitation of the article. (Not because NONMEM is not a suitable package to use but because it is the only package used.) For example, Makubate and Senn, modelling the effects of cross-over trials in infertility, found some differences depending on whether SAS, GenStat or R were used to implement what was ostensibly the same model, or indeed program it from scratch using Mathcad and in the field of estimating values below the limit of quantitation Senn, Holford and Hockey got different standard errors using NOMEM compared to SAS, GenStat and R, although such differences are not necessarily inherent to packages but may reflect implementation.

On a more technical matter, the author has used a discrete mixture which some might regard as being excessively restrictive and a little unrealistic, although the author does claim "the published data do not support a model of uni-modal, albeit varied, fecundability". A further issue is that unlike for causal studies, such as clinical trials, the degree to which the subjects studied are representative of a population of interest is important. Lacking knowledge of this particular field 
and the studies cited I cannot judge whether this condition is satisfied. It seems at least plausible that sub-fertile couples are more likely to be studied than those of average fertility.

Nevertheless, this seems to be an interesting and valuable exercise in modelling a difficult field.

\section{References}

1. Makubate B, Senn S: Planning and analysis of cross-over trials in infertility.Stat Med. 2010; 29 (30): 3203-10 PubMed Abstract | Publisher Full Text

2. Senn S, Holford N, Hockey H: The ghosts of departed quantities: approaches to dealing with observations below the limit of quantitation.Stat Med. 2012; 31 (30): 4280-95 PubMed Abstract I Publisher Full Text

Competing Interests: No competing interests were disclosed.

I confirm that I have read this submission and believe that I have an appropriate level of expertise to confirm that it is of an acceptable scientific standard.

Author Response 29 Nov 2016

Gavin Jarvis, University of Sunderland, UK

I would like to thank Professor Senn for his remarks ${ }^{1}$. I respond to his comments as follows:

1. Representative Populations: This is an important point and Prof. Senn's intuitive concern is well-founded. The analysis attempts to introduce a little more focus to the data from the three particular studies ${ }^{2-4}$. Despite the similarities between the quantitative conclusions from the three studies, extrapolation to a general population is risky, given the known and likely variances in fertility associated with age, health and social status, level of education, ethnicity etc... However, the strength of these studies lies in the detail and density of the data, which is rare among other similar studies, and I believe this re-analysis does yield some additional insight. I have addressed some of the concern regarding differences in populations and other sources of reproductive variance in another article 5 .

2. Conditional Probabilities: I hope the following makes my intention more explicit.

If $P(A \mid B)$ is the probability of event $A$, conditional on event $B$, then:

(i) $\pi_{L B}=P(A \mid B)$, where $A$ is a live birth, and $B$ is a clinical pregnancy

(ii) $\pi_{C L I N}=P(A \mid B)$, where $A$ is a clinical pregnancy, and $B$ is a positive hCG test

(iii) $\pi_{H C G}=P(A \mid B)$, where $A$ is a positive $h C G$ test, and $B$ is successful fertilisation

(iv) $\pi_{F E R T}=\mathrm{P}(\mathrm{A} \mid \mathrm{B})$, where $\mathrm{A}$ is successful fertilisation, and $\mathrm{B}$ is the in vivo co-localisation of ovum and sperm

(v) $\pi_{S O C}=P(A \mid B)$, where $A$ is the in vivo co-localisation of ovum and sperm, and B a single menstrual cycle

3. Discrete mixture model: I agree that dividing the cohort into two discrete populations is a little unrealistic. However, in the absence of the original raw data, there is little else that could be done. The data conform markedly better to this bimodal distribution, as compared to either a uni-modal or tri-modal model. I doubt if 
this model captures all the quantitative subtlety that subsists in the data; nevertheless, it does both confirm and quantify, albeit perhaps a little brutally, the clear impression expressed in the original reports that the study populations included subjects who were sub-fertile.

4. Modelling packages: The point about differing outputs from different modelling software packages is also well made. My own instinct (which is admittedly not as refined as Prof. Senn's) is that any difference is likely to be small, since, although I used NONMEM, there is no random effect (i.e., OMEGA) modelling other than the residual error variance (i.e., SIGMA). However, there are perhaps other reasons why performing the analysis in GenStat or $\mathrm{R}$ is preferable. At some point I will repeat the analysis and report back any differences in the output.

I shall incorporate changes relating to points 1, 2 and 3 into a second version of the article.

\section{References}

1. Senn SJ: Referee Report For: Estimating limits for natural human embryo mortality [version 1; referees: 2 approved]. F1000Research. 2016; 5: 2083.

2. Wilcox AJ, Weinberg CR, O'Connor JF, et al.: Incidence of early loss of pregnancy. $N$ EnglJ Med. 1988; 319(4): 189-94. PubMed PMID: 3393170.

3. Zinaman MJ, Clegg ED, Brown CC, et al.: Estimates of human fertility and pregnancy loss. Fertil Steril. 1996; 65(3): 503-9. PubMed PMID: 8774277. Epub 1996/03/01. eng.

4. Wang X, Chen C, Wang L, et al.: Conception, early pregnancy loss, and time to clinical pregnancy: a population-based prospective study. Fertil Steril. 2003; 79(3): 577-84. PubMed PMID: 12620443. Epub 2003/03/07. eng.

5. Jarvis GE: Early embryo mortality in natural human reproduction: What the data say [version 1; referees: awaiting peer review]. F1000Research. 2016; 5: 2765.

Competing Interests: No competing interests were disclosed. 
The benefits of publishing with F1000Research:

- Your article is published within days, with no editorial bias

- You can publish traditional articles, null/negative results, case reports, data notes and more

- The peer review process is transparent and collaborative

- Your article is indexed in PubMed after passing peer review

- Dedicated customer support at every stage

For pre-submission enquiries, contact research@f1000.com 